\title{
A Compact Low-Profile High Isolation MIMO Antenna For X-Band Applications
}

\author{
Akanksha Singh ( $\nabla$ akankshasingh5614@gmail.com ) \\ National Institute of Technology Kurukshetra \\ Arvind Kumar \\ National Institute of Technology Kurukshetra \\ Binod Kumar Kanaujia \\ JNU: Jawaharlal Nehru University
}

\section{Research Article}

Keywords: Diversity, isolation, MIMO antenna, neutralization line, planar

Posted Date: July 13th, 2021

DOI: https://doi.org/10.21203/rs.3.rs-662037/v1

License: (1) This work is licensed under a Creative Commons Attribution 4.0 International License. Read Full License 


\title{
A Compact Low-Profile High Isolation MIMO Antenna for X-band Applications
}

\author{
Akanksha Singh ${ }^{1}$, Arvind Kumar ${ }^{2}$, Binod Kumar Kanaujia ${ }^{3}$, \\ ${ }^{1}$ Electronics and Communication Engineering Department, Amity University, Greater Noida \\ 201308, India \\ ${ }^{2}$ Electronics and Communication Engineering Department, National Institute of Technology, \\ Kurukshetra, Haryana 136119, India \\ ${ }^{3}$ School of Computational and Integrative Sciences, Jawaharlal Nehru University, New Delhi \\ 110067, India \\ 19akankshasingh5614@gmail.com, ${ }^{2}$ arvind_sharma@ntkkr.ac.in, ${ }^{3}$ bkkanaujia@ieee.org,
}

\begin{abstract}
A novel compact low profile MIMO antenna is designed and implemented with high isolation for the $\mathrm{X}$ band applications. Proposed MIMO geometry is incorporated with two monopoles which are excited by $50 \Omega$ feed line. To enhance the isolation between inter-elements meander line structures are is identically placed. These meander line structures are reducing the mutual coupling up to $26 \mathrm{~dB}$. In the proposed MIMO antenna two elements cover the entire frequency range between 7.4-11.8 GHz for the $\mathrm{X}$ band applications. Meander line structure is working as a decoupling network which improves the isolation considerably. The overall size of the MIMO antenna is $25 \times 30 \times 1 \mathrm{~mm}^{3}$, and it offers inter-element isolation of $>26 \mathrm{~dB}$, envelope correlation coefficient is less than 0.2 , and directivity gain $>9.99$ over the resonating frequency range. The proposed MIMO antenna model is fabricated, and measurement results are verified with simulated results. The antenna shows the satisfactory gain of around $4.8 \mathrm{~dB}$ in entire frequency range. The antenna shows the satisfactory gain of around $4.5 \mathrm{~dB}$ in entire frequency range.
\end{abstract}

Keywords: Diversity, isolation, MIMO antenna, neutralization line, planar 


\section{Introduction}

Multiple-input-multiple-output antennas are made up of numerous resonating elements on both sides of the transmitting networks to bring off high data rate without increasing communication bandwidth or power. Since multiple resonators are integrated into a single wireless system/device, the size of the multi-input-multi-output (MIMO) antenna is an important design factor. The major challenge in the MIMO configuration is to improve isolation between the antenna elements when they are closely placed. In the past, numerous methods have been incorporated to upgrade inter-element isolation, such as slits/slots on the ground plane, defected ground structure (DGS), electromagnetic band-gap (EBG), split ring resonator (SRR), neutralization lines (NL), etc.

In [1], an eight-shaped stub was used to reduce the mutual coupling of the inter-elements, but the size of the antenna was much larger. In [2], mutual coupling has been significantly reduced by decoupling network, but system complexity has increased. In [3], the dual-band MIMO antenna is designed with DGS, in which a high degree of isolation between the antenna components is achieved. In [4], a MIMO antenna antenna for four WLAN applications was introduced, in which the $\lambda / 4$ terminal network is used to improve isolation. An inverted F-antenna (PIFA) two-port antenna has been reported in [5], where two feed plates were used to strengthen the isolation. In [6], two dummy elements were used to improve the isolation of the elements, but the process of dummy construction was complicated and the size of the antenna was very large. The structure of the earth plays a very important role in equating impedance and development alone, as discussed in [7].Although the isolation techniques mentioned above are somewhat effective, only a few of them can be used on closely packed antenna systems. Therefore, one of the simplest methods for improving isolation is to introduce slits and slots in the ground plane. In [8], an ultra-wideband (UWB) antenna was developed with a strip on its bottom plane, which offered an additional current path and also improved the impedance matching. In [9], a strip was 
positioned under the radiating element to provide an additional coupling path to improve isolation. In [10], a MIMO antenna consisted of two X-shaped arms was presented, which functioned as a self-decoupling structure. In [11], the antenna consisted of two uniform radiators, and a ground-coupled loop-shaped decoupling structure was present between them. The decoupling element was used as a series resonator network, and comprised of lumped components. An antenna with two frequency reconfigurable monopole elements placed symmetrically was reported in [12], where pin diodes and DGS were used for inter-element correlation enhancement.

The paper presents the design of a planar compact multi-input-multi-output (MIMO) antenna for mutual communication between antenna elements. These are low-profile MIMO antennas suitable for X-band applications. The prepared antenna contains two identical monopole emitters, a modified bottom plane, and, linear meandered-line decoupling geometry to improve insulation. The antenna operates in the frequency range from $7.4 \mathrm{GHz}$ to $11.8 \mathrm{GHz}$ for excellent isolation of the entire band. The MIMO antenna size is $25 \times 30 \mathrm{~mm} 2$. Despite being low profile, these antennas have a very high isolation rate of no more than $26 \mathrm{~dB}$ For modeling and optimization, it is suggested to use a 3D EM modeling antenna, Ansys HFSS.

\section{Antenna Configuration}

The initial design started with a simple monopole emitter with a $1 \mathrm{~mm}$ high substrate and a partially grounded plane on the other side of the substrate. A rectangular plane, the space is modified to get the operation, X-band. The entire contents of the MIMO antenna are $30 \times 25 \times 1$ $\mathrm{mm} 3$, as shown in the photo.1 (ant. 1). At present, our goal is that the MIMO antenna design is using a simple monopole radiator antenna, good characteristics, at the same time, they should correspond to the same band behavior, it turns out that the monopole radiator. We designed a two-element MIMO antenna, with two same monopole radiators in one plane (ant. 2). The two elements are positioned in such a way that without the need to change the size of ground plane with as previous band performance. Two meander design lines inserted between two elements to reduce mutual coupling (ant 3). Here, the lower line structure increases the carrying capacity of the resistance by increasing the surface area of the current path. This is done in three stages, which are used in the development of the proposed ant-1 design, as indicated in the photo.1, ant2 , and finally the proposed design of the ant-3 line, respectively. The subsets of proposed 
structure (ant 1 and ant 2) are simulated to examine the performance of this subsection, individually. The design of the MIMO antenna module is shown in Fig. 1 (c)). Antenna in FR-4 dielectric materials $(\xi \mathrm{r}=4.4, \delta=0.02$ thickness $=1.6 \mathrm{~mm})$. The monopole radiator is located on the upper side of the dielectric substrate, and partially ground surface (L2 $\times$ L3) is located down. Each monopole emitters have a $50 \mathrm{ohm}$ microstrip feed line. The monopole element is selected to improve the performance of a compact size. Two meandered-line structures are placed in between the antenna elements and the isolation is improved appreciably. The ANSYS HFSS® 3D-EM-a tool is used to simulate a MIMO antenna. The dimensions of the antenna offer are given in the Table 1 below.
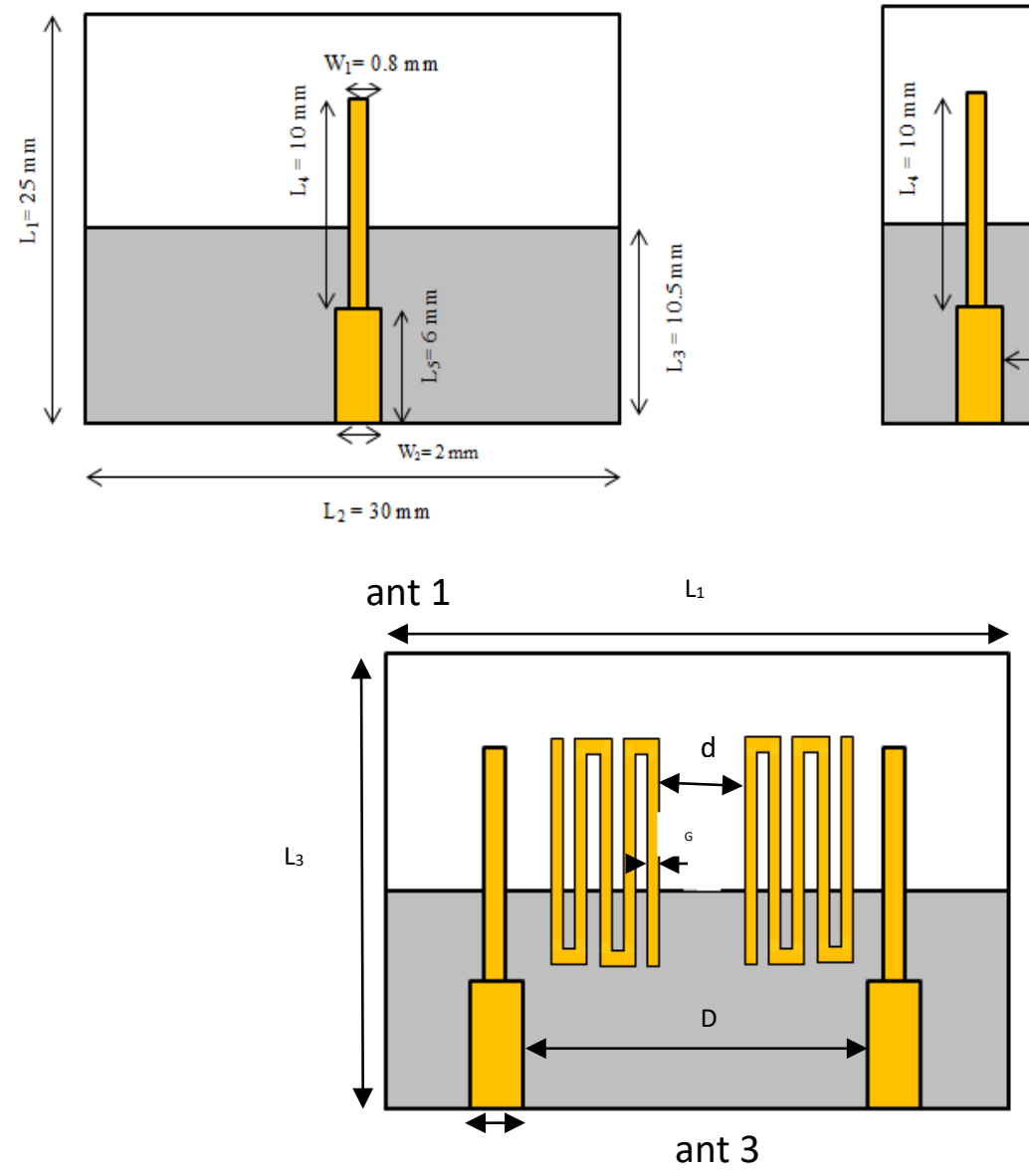

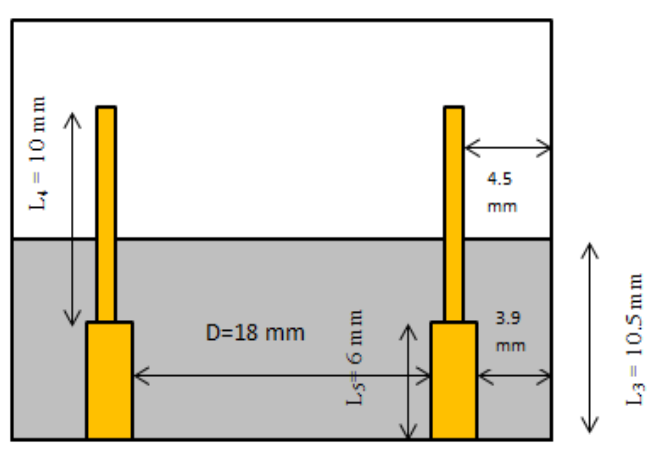

ant 2

Figure 1. Evolution steps of Suggested MIMO antenna. 
Table 1. Design parameters of the proposed MIMO antenna.

\begin{tabular}{|c|c|c|c|}
\hline Parameter & Unit (mm) & Parameter & Unit (mm) \\
\hline$L_{1}$ & 25 & $W_{3}$ & 4.5 \\
\hline$L_{2}$ & 30 & $d$ & 6 \\
\hline$L_{3}$ & 10.5 & $D$ & 18 \\
\hline$L_{4}$ & 10 & $K$ & 12 \\
\hline$L_{5}$ & 6 & $G$ & 0.5 \\
\hline$W_{1}$ & 0.8 & $J$ & 1 \\
\hline
\end{tabular}

The ground plane geometry is optimized to attain the desired band performance. Figure 2 shows the reflection coefficients and $S_{11}$ and $S_{21}$ of all iterations. The isolation of Ant. 2 is $8 \mathrm{~dB}$, which is extremely low and inadequate for MIMO antennas. In Ant. 3, two rectangular-shaped meander lines are placed in the middle of antenna elements for better inter-element isolation. The meander lines offer a stop band property and minimize the mutual coupling between the resonating radiators. The distance between the meander lines is optimized to decrease mutual coupling and improve impedance matching. It is observed from Figure 2 that isolation significantly increases with a little change in impedance bandwidth.

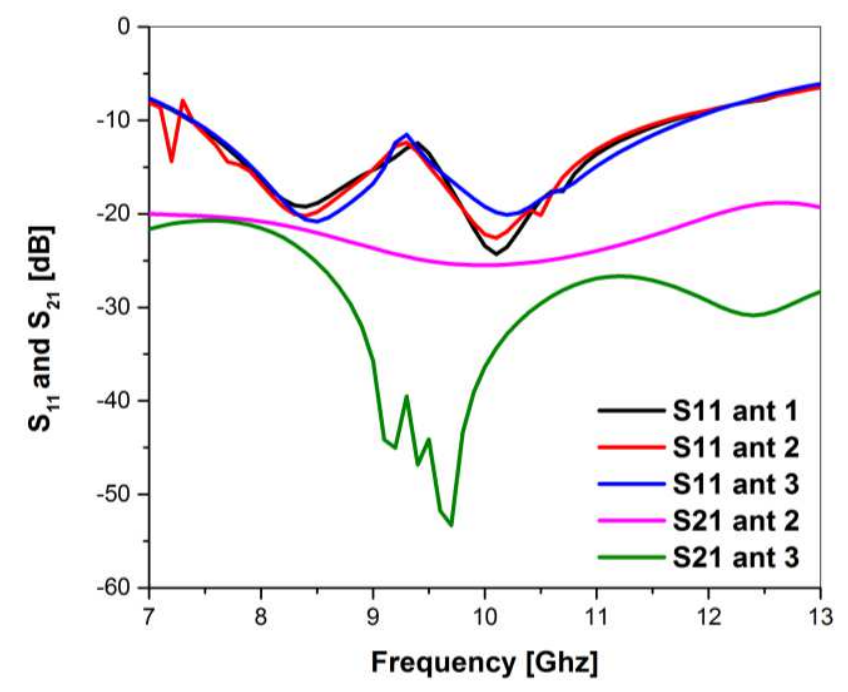

Figure 2. Simulated $S_{11}$ and $S_{21}$ of the antenna design steps.

\subsection{Parametric Study}


These are parameters of the meander line structure and its effect on the MIMO antenna properties. A parametric study shows that parameters $(\mathrm{J}, \mathrm{K})$ and $(\mathrm{G})$ show a significant effect on isolation, as shown in Figure 3(a), (b) and (c). Another parameter changes, the other remains unchanged. 3 (a) increases when the isolation parameter $J$ between antenna elements decreases. Variable time, length, and $\mathrm{K}$ of the spiral part, there is a slight decrease in inter-element isolation, as shown in Fig. 3 (a) (b). As can be seen from Fig. 3 (c), the isolation between antenna elements is significantly reduced due to an increase in parameter $\mathrm{G}$.

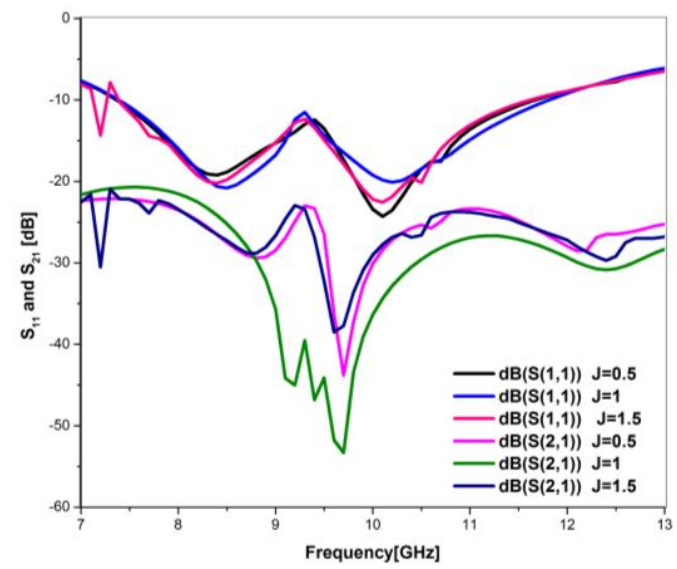

(a)

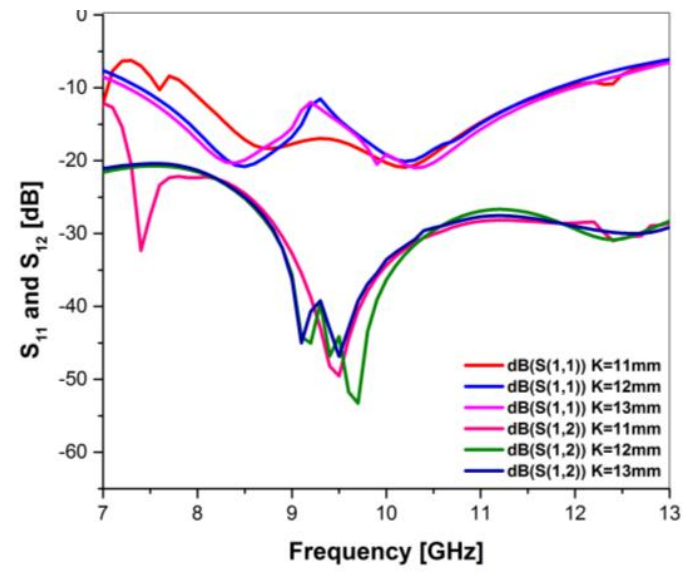

(b) 


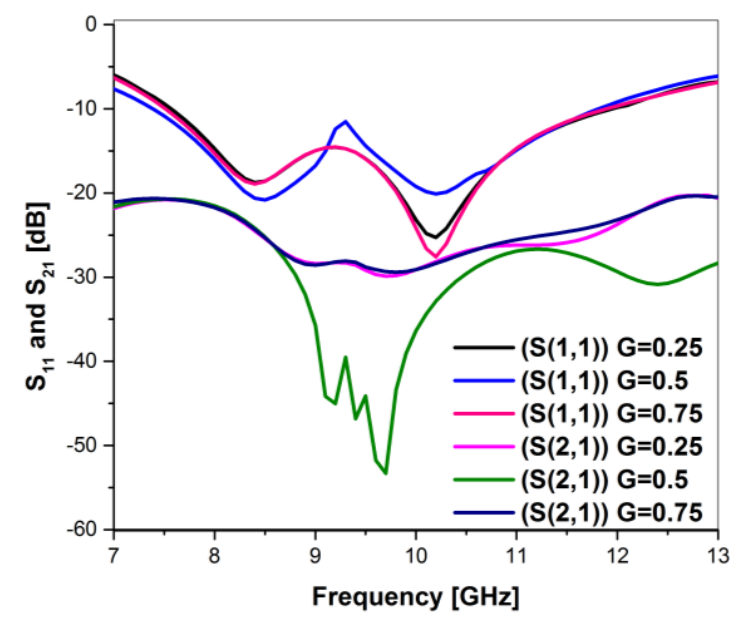

(c)

Figure 3. Parametric study of the proposed MIMO antenna: (a) alteration of $J$, (b) alteration of $K$, (c) alteration of $G$.

\section{Results and Discussion}

Multi-input multi-input antenna (MIMO) was designed and quantified to confirm the proposed designs. Top and bottom view of the prepared antenna prototype is shown in Fig. 4(a) and (b). To measure the reflection coefficients of the MIMO antenna, use the Agilent N5230A vector network analyzer. Based on the sample and sizes S11 and S21, compare the Figure.5. Apparently, there is a good agreement on the sample and dimensions of the S-parameters. Introduced MIMO antenna, meander line structures, greatly improves various insulation elements. Application before the meander line, the isolation structure between the antenna elements, was not $8 \mathrm{~dB}$, which increased by more than $26 \mathrm{db}$ and after the meander line was passed, the structure between the two radiating monopoles.
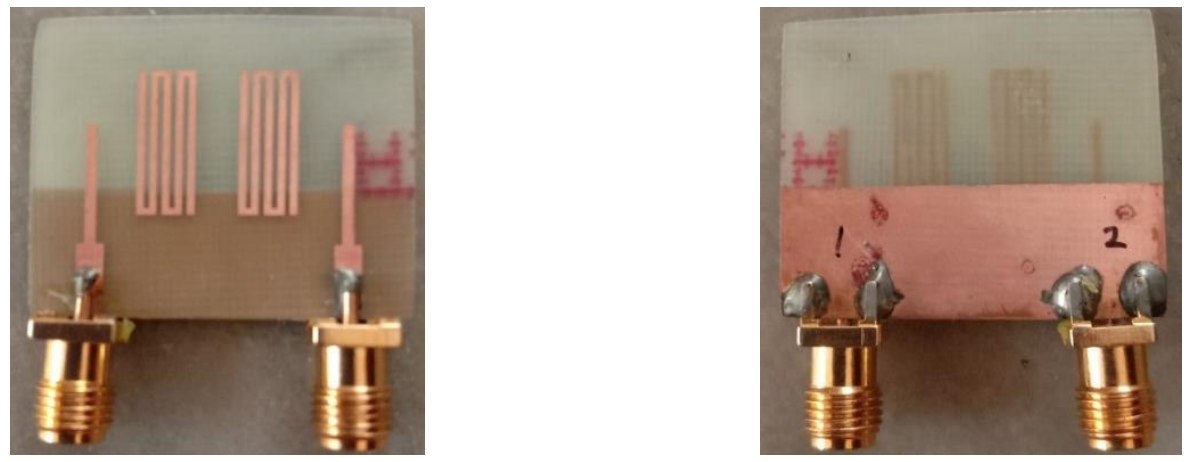
Figure 4. Fabricated prototype of the MIMO antenna: (a) top view, (b) bottom view.

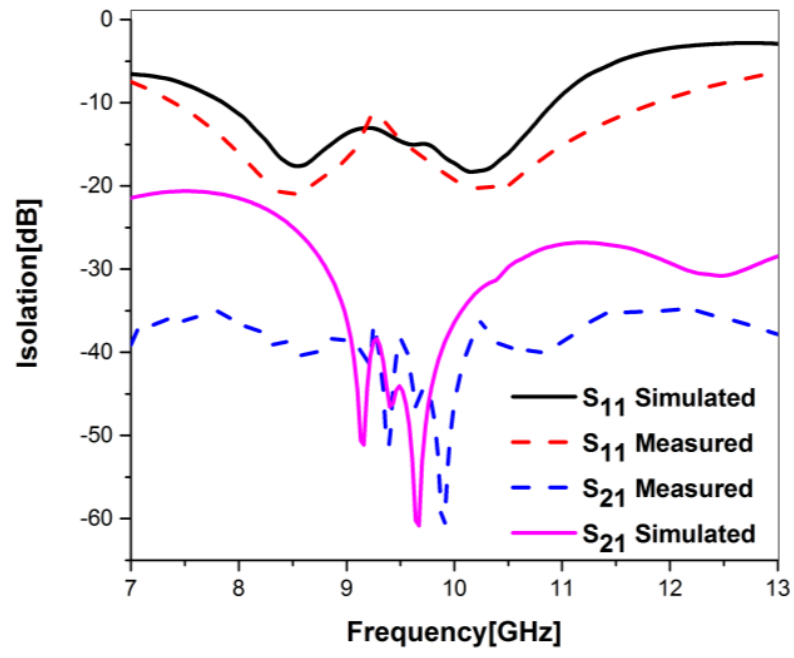

Figure 5. S-parameters of the proposed MIMO antenna.

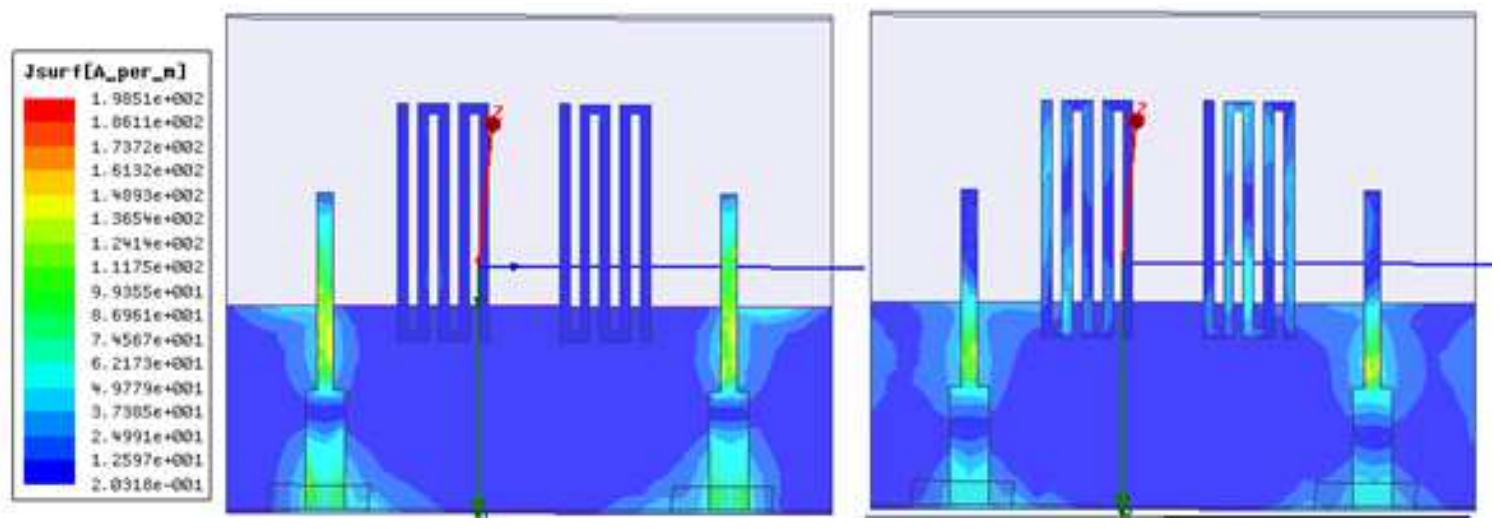

Figure 6. Surface current distribution of the proposed MIMO antenna: (a) $8.5 \mathrm{GHz}$, (b) $9.9 \mathrm{GHz}$.

Figure. 6 shows the distribution of the surface current frequency from 8.5 and 9.9 Ghz. It can be seen that the current minimum number of meander lines shows what isolation between the two monopole emitters is needed.

The gain and efficiency of radiation are shown in Figure. 7. The maximum gain of the recording antenna is about $4.5 \mathrm{~dB}$, and the average efficiency is $95 \%$. 


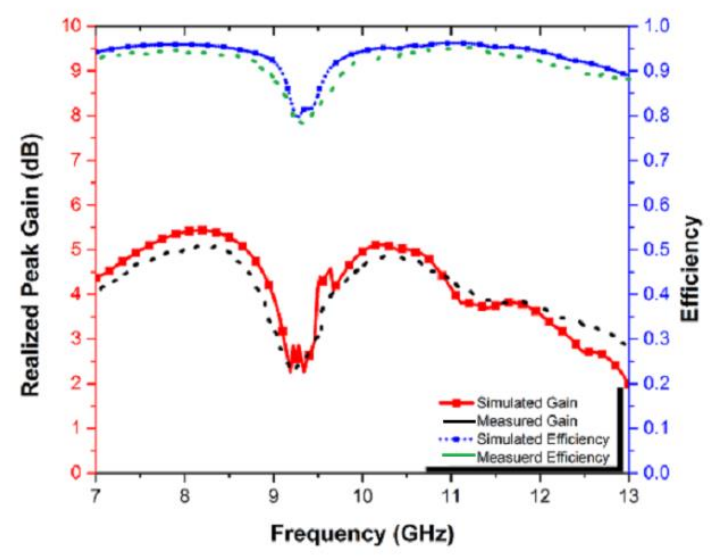

Figure 7. Gain and efficiency of the proposed MIMO antenna.

Figure 8 shows the radiation patterns of the MIMO antenna at $8.5 \mathrm{GHz}$ and $9.9 \mathrm{GHz}$. Figure 8 shows the radiation patterns of the MIMO antenna at $8.5 \mathrm{GHz} /$ Airplane, $8.5 \mathrm{GHz} / \mathrm{H}$ plane, 9.9 $\mathrm{GHz} / \mathrm{E}$ plane and $9.9 \mathrm{GHz} / \mathrm{H}$-plane. The results produced and measured show a reasonable agreement between them. Minor deviations are due to structural and measurement errors.

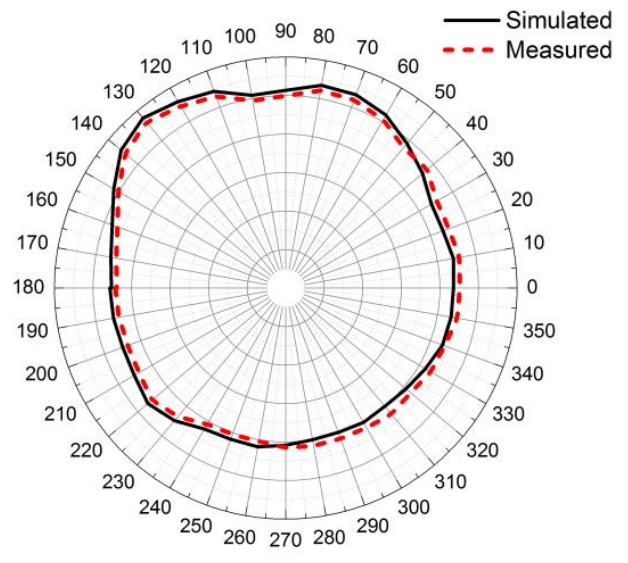

(a) E Plane at $8.5 \mathrm{GHz}$

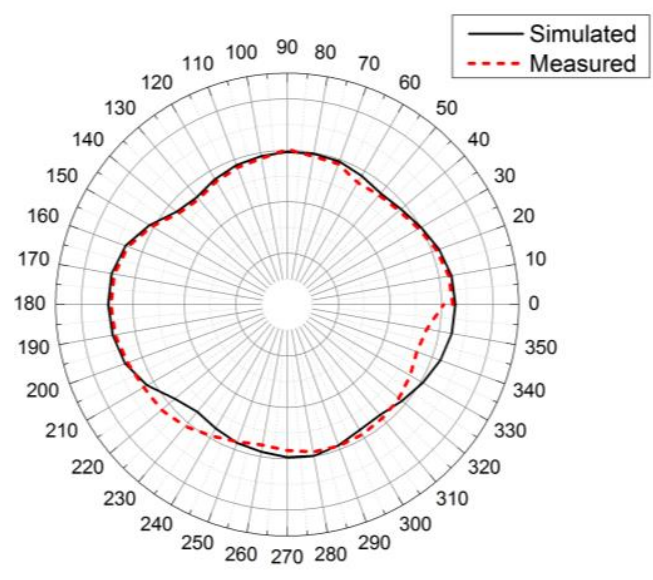

(b) $\mathrm{H}$ Plain at $8.5 \mathrm{GHz}$ 


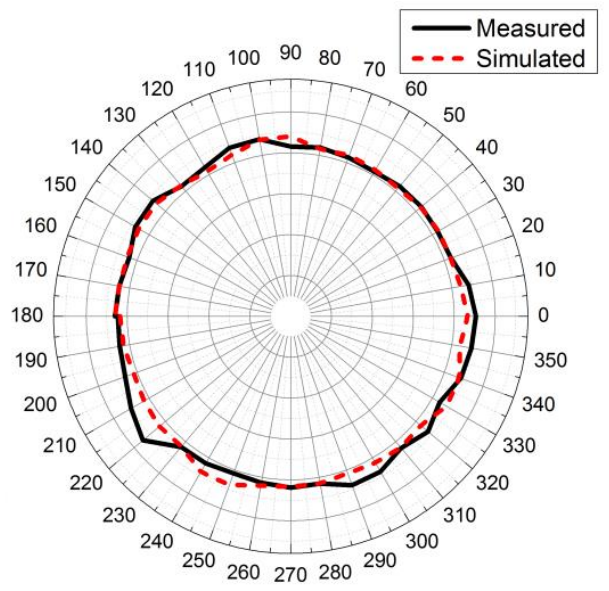

(c) E Plane at $9.9 \mathrm{GHz}$

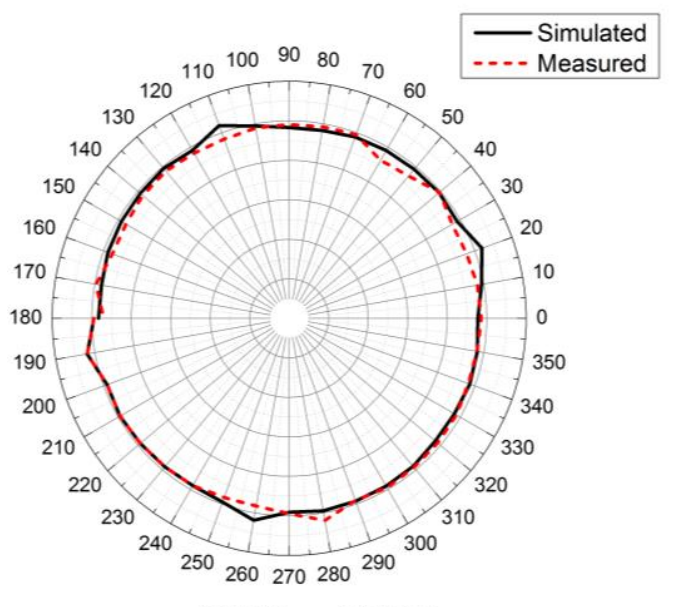

(d) H Plane at $9.9 \mathrm{GHz}$

Figure 8. Radiation patterns of the MIMO antenna: (a) $8.5 \mathrm{GHz} / \mathrm{E}-$ plane, (b) $8.5 \mathrm{GHz} / \mathrm{H}-$ plane, (c) 9.9 GHz/E-plane, (d) $9.9 \mathrm{GHz} / \mathrm{H}-$ plane.

\section{MIMO Performance}

In MIMO, diversity and multiplexing parameters, such as the coefficient of envelope integration ECC, DG, TARC, CCL and mean effective gain (MEG) ), it is important to ensure the functionality of the proposed structure. The ECC shows the interaction between the two antenna components and can be given as [21]

$$
\rho=\frac{\left|S i{ }^{*} S i j+S j i^{*} S j j\right|^{2}}{\left(\left(1-|S i i|^{2}+|S j i|^{2}\right)+\left(1-|S j j|^{2}+|S i j|^{2}\right)\right)}
$$

The ECC for the proposed antenna design is given in Figure.9. It is noted that the ECC is less than 0.2 in the operating frequency band, which satisfies an acceptable limit of $<0.5$. From the result, it can be concluded that the proposed design provides good performance for diversity. 


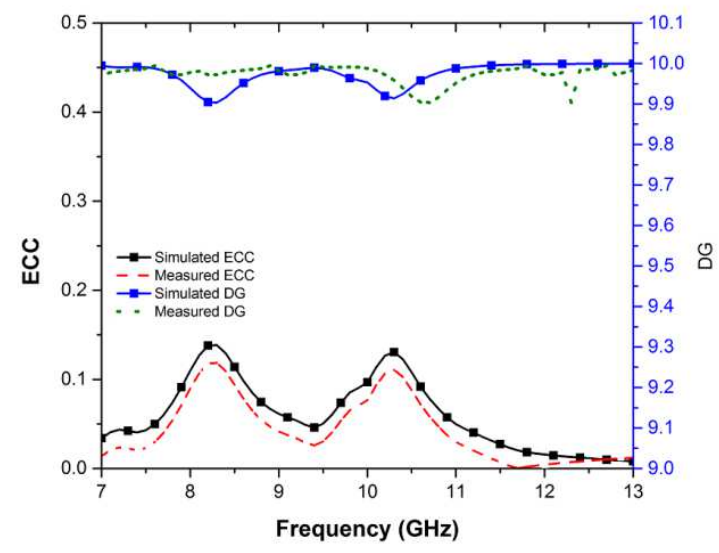

Figure 9. ECC and DG of the presented MIMO antenna.

DG is another leading parameter of the MIMO antenna. It is used to determine the diversity effectiveness and is calculated as

$$
D G=10 \sqrt{1-E C C^{2}}
$$

A high DG (>9.9) is noticed in the operating frequency band of the MIMO antenna.

In the MIMO system, the neighboring antenna elements influence each other's performance. As a result, the overall operating frequency range and efficiency of the multiport antenna are affected when the antenna elements work together. TARC is taken into account to calculate this effect and is described as the ratio of the square root of total reflected power to the total incident power [21].

$$
T A R C=\sqrt{\frac{(\mathrm{Sii}+\mathrm{Sij})^{2}+(\mathrm{Sji}+\mathrm{Sjj})^{2}}{2}}
$$




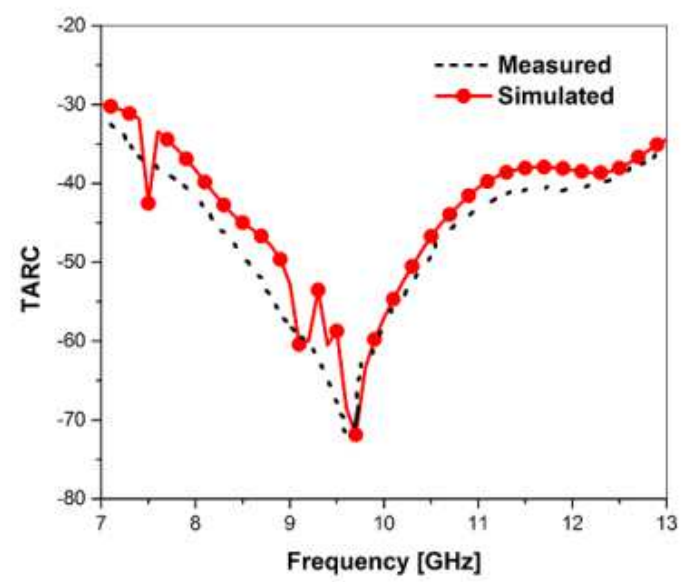

Figure 10. TARC of the proposed MIMO antenna.

The measured and simulated TARC of the proposed MIMO antenna are presented in Figure 10.

CCL is another significant variable to evaluate the diversity performance of the MIMO antenna system. The maximum limit of transmission and reception is characterized by CCL, and it can be evaluated as [21]

where

$$
\begin{aligned}
C C L & =-\log _{2}\left(\psi^{R}\right) \\
\psi^{R} & =\left[\begin{array}{ll}
\psi_{i i} & \psi_{i j} \\
\psi_{j i} & \psi_{j j}
\end{array}\right]
\end{aligned}
$$

$$
\begin{aligned}
& \psi_{i i}=1-\left(\left|S_{i i}\right|^{2}+\left|S_{i j}\right|^{2}\right) \\
& \psi_{j j}=1-\left(\left|S_{j i}\right|^{2}+\left|S_{j j}\right|^{2}\right) \\
& \psi_{j i}=-\left(S_{i i}^{*} S_{j i}+S_{j i}^{*} S_{j j}\right) \\
& \psi_{i j}=-\left(S_{j j}{ }^{*} S_{j i}+S_{i i}{ }^{*} S_{i j}\right)
\end{aligned}
$$

The CCL is conveyed in Figure 11(a), and it is noticed that the channel capacity loss (CCL) is less than $-0.2 \mathrm{~dB}$. 
MEG is another important parameter to evaluate the diversity performance of the MIMO systems. It is a measure of the median power obtained from the event power used and can be determined as [21]

$$
\begin{aligned}
& M E G 1=0.5\left(1-\left|S_{i i}\right|^{2}+\left|S_{i j}\right|^{2}\right) \\
& M E G 2=0.5\left(1-\left|S_{i j}\right|^{2}+\left|S_{j j}\right|^{2}\right) \\
& M E G=M E G 1-M E G 2
\end{aligned}
$$

Measurements and simulations show that the proposed MIMO antenna is indicated in Figure 11 (b). This MIMO antenna show the MEG is less than $3 \mathrm{~dB}$, which is below the acceptable limit.

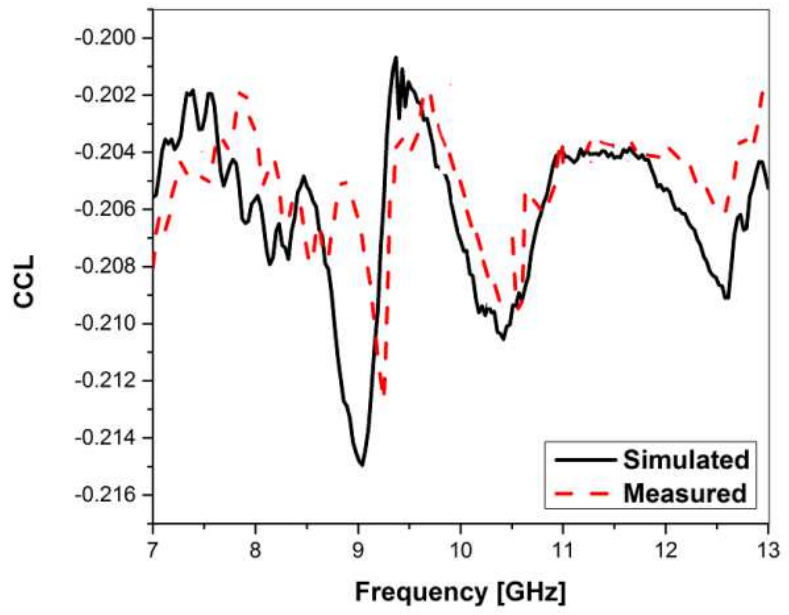

(a)

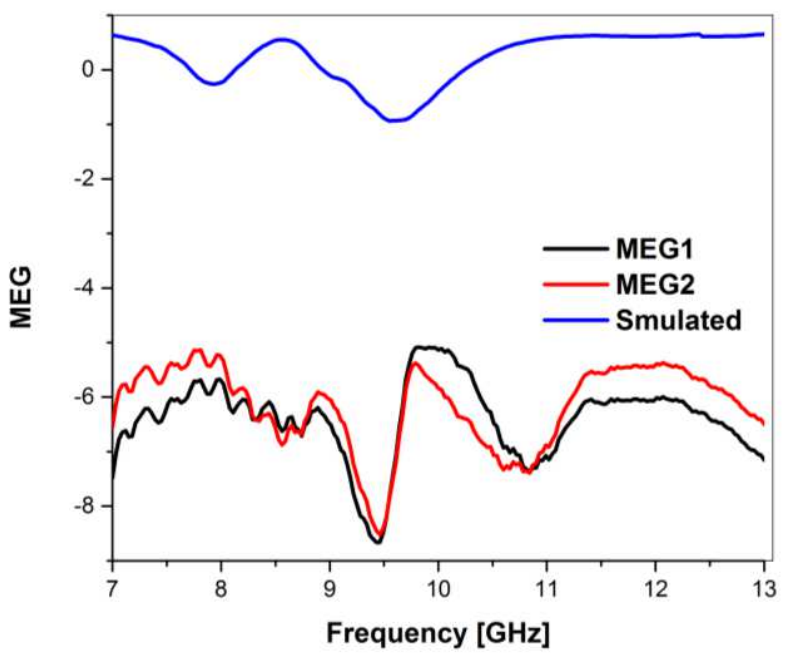


(b)

Figure 11. Proposed MIMO antenna: (a) CCL, (b) MEG.

Furthermore, the proposed MIMO antenna is compared with the previously presented MIMO antennas shown in the Table2. The structure, small size and low mutual coupling are proposed and in accordance with it for use in the X-band.

Table 2. Comparison with the previously reported MIMO antennas.

\begin{tabular}{|c|c|c|c|c|c|c|}
\hline Ref. & $\begin{array}{c}\text { Size }(\mathrm{mm} \times \\
\mathrm{mm})\end{array}$ & Gain (dB) & $\begin{array}{c}\text { Efficiency } \\
(\%)\end{array}$ & $\begin{array}{c}\text { Resonating } \\
\text { Bandwidth } \\
(\mathrm{GHz})\end{array}$ & Isolation $(\mathrm{dB})$ & ECC \\
\hline [1] & $55 \times 35$ & 6.9 & --- & $2.74-12.33$ & $>26$ & $<0.026$ \\
\hline$[2]$ & $40 \times 80$ & 5 & 59 & $\begin{array}{l}2.4-2.5 \\
5.1-5.8\end{array}$ & $>20$ & $<0.2$ \\
\hline [3] & $50 \times 100$ & 2.4 & --- & $0.803-0.823$ & $>17$ & $<0.21$ \\
\hline [7] & $38.5 \times 38.5$ & 4.5 & 75 & $3.5,5.2,5.8$ & $>15$ & $<0.02$ \\
\hline [9] & $60 \times 48$ & 4.6 & 80 & $\begin{array}{c}3.4-3.7 \\
5.15-5.35\end{array}$ & $>17.2$ & $<0.002$ \\
\hline [12] & $40 \times 40$ & 5.8 & --- & $1.88-2.64$ & $>41.2$ & $<0.005$ \\
\hline [18] & $40 \times 70$ & 3.2 & 70 & 4.82 & $>23.5$ & $<0.05$ \\
\hline [20] & $48 \times 48$ & $<3$ & $\begin{array}{l}-- \\
--\end{array}$ & $2.5-12$ & $>18$ & $\begin{array}{l}-- \\
--\end{array}$ \\
\hline [21] & $40 \times 40$ & $\begin{array}{c}5.1-5.8, \\
7.25-7.75\end{array}$ & --- & $3.4-12$ & $>15$ & --- \\
\hline Prop. & $25 \times 30$ & 4.2 & 95 & $7.4-11.8$ & $>26$ & $<0.2$ \\
\hline
\end{tabular}

\section{Conclusion}

In this work, a low-profile compact size MIMO antenna is proposed for X-band $(7.4 \mathrm{GHz}-11.8$ $\mathrm{GHz}$ ) applications. Each antenna element consists of microstrip fed monopole radiator and a common ground plane. Two meandered-line elements are introduced between the radiating elements to enhance isolation. The antenna configuration is fabricated and measured result the 
agreement between the measured and simulated result. The proposed MIMO antenna offers inter-element isolation greater than $26 \mathrm{~dB}$ and a gain of $\sim 4 \mathrm{dBi}$ in the resonating frequency band. Various MIMO performance parameters, such as ECC, DG, TARC, CCL, and MEG, are examined and found within acceptable limits. The MIMO antenna configuration present in this work can be used for the $\mathrm{X}$ band applications in the wireless communication systems.

\section{Declarations}

\section{Acknowledgements}

The authors did not receive support from any organization for the submitted work.

The authors declare they have no financial interests.

\section{Author information}

\section{Affiliations}

Akanksha Singh

Electronics and Communication Engineering Department, Amity University, Greater Noida 201308, India

Arvind Kumar

Electronics and Communication Engineering Department, National Institute of Technology, Kurukshetra, Haryana 136119, India

Binod Kumar Kanaujia

School of Computational and Integrative Sciences, Jawaharlal Nehru University, New Delhi 110067, India

Corresponding author

Correspondence to Akanksha Singh

\section{Ethics declarations}

\section{Conflict of interest}

The author declared that there is no conflict of interest. 
Data are available on request due to privacy or other restrictions

\section{References}

[1] Ashim Kumar Biswas ,Ujjal Chakraborty 'Compact wearable MIMO antenna with improved port isolation for ultra-wideband applications', IET Microwave Antennas Propagation 2019, 13, (4), pp. 498-504

[2] Sreenath Reddy Thummaluru, Rajkishor Kumar, Raghvendra Kumar Chaudhary, 'Isolation and frequency reconfigurable compact MIMO antenna for wireless local area network applications', IET Microwave. Antennas Propagation., 2019, 13, (4), pp. 519-525.

[3] Mohammad S. Sharawi, Senior Member, Ahmed B. Numan, Muhammad U. Khan, and Daniel N. Aloi, Senior Member, "A Dual-Element Dual-Band MIMO Antenna System with Enhanced Isolation for Mobile Terminals," IEEE Antennas Wireless Propag. Lett., vol. 11, pp. 1006-1009, 2012.

[4] Saber Soltani, ParisaLotfi and Ross D. Murch, "A Port and Frequency Reconfigurable MIMO Slot Antenna for WLAN Applications", IEEE Transactions On Antennas And Propagation, Vol. 64, No. 4, April 2016. pp.1209-1217.

[5] H. T. Chattha, M. Nasir, Q. H. Abbasi, Y. Huang, and S. S. Alja'afreh, "Compact low-profile dual-port single wideband planar inverted-f MIMO antenna," IEEE Antennas Wireless Propag. Lett., vol. 12, pp. 1673-1675, 2013.

[6] Jing-Ya Deng, Jin-Yong Li, Li-XinGuo, "Decoupling of a Three-Port MIMO Antenna with Different Impedances Using Reactively Loaded Dummy Elements", IEEE Antennas and Wireless Propagation Letters, 2018

[7] R. Karimian, H. Oraizi, S. Fakhte, and M. Farahani, "Novel F-shaped quad-band printed slot antenna for WLAN and wimax MIMO systems,"IEEE Antennas Wireless Propag.Lett., vol. 12, pp. 405-408, 2013.

[8] Le Kang, Hui Li, Xinhuai Wang, and Xiaowei Shi, "Compact Offset Microstrip-Fed MIMO Antenna for Band-Notched UWB Applications,” IEEE Antennas Wireless Propag. Lett., vol. 14, pp. 405-408, 2015.

[9] Tzu-Chun Tang, and Ken-Huang Lin, "An Ultrawideband MIMO Antenna With Dual BandNotched Function,” IEEE Antennas Wireless Propag. Lett., vol. 13, pp. 1076-1079, 2014. 
[10] Han Wang, Zhijun Zhang and Zhenghe Feng.," Dual-port planar MIMO antenna with ultra-high isolation and orthogonal radiation patterns", ELECTRONICS LETTERS 8th January 2015 Vol. 51 No. 1 pp. 7-8.

[11] L. Qu, R. Zhang, and H. Kim, "Decoupling between ground radiation antennas with ground-coupled loop-type isolator for WLAN applications," Microwave., Antennas Propag., vol. 10, no. 5, pp. 546-552, 2016.

[12] Y. Cao, S.W. Cheung, and T. I. Yuk, "Frequency-reconfigurable multiple input-multipleoutput monopole antenna with wide-continuous tuning range," Microwave., Antennas Propag., vol. 10, no. 12, pp. 1322-1331, 2016.

[13] Ahmed Alieldin , Yi Huang, et. al, "A Dual-Broadband Dual-Polarized Fylfot-Shaped Antenna for Mobile Base Stations Using MIMO Over-Lapped Antenna Subarrays," IEEE Access, vol. no.6,pp. 50260-50271,2019

[14] A. Ramachandran, S. Mathew, V. Rajan, and V. Kesavath, "A compact triband quadelement MIMO antenna using SRR ring for high isolation,'IEEE Antennas Wireless Propag.Lett., vol. 16, pp. 1409-1412, 2017.

[15] Kanhaiya Sharma, and Ganga Prasad Pandey, " Two Port Compact MIMO Antenna for ISM Band Applications", Progress In Electromagnetics Research C, Vol. 100, pp. 173-185, 2020. [16] L. Kang, H. Li, X. Wang, and X. Shi, "Compact offset microstripfed MIMO Antenna for band-notched UWB applications," IEEE Antenna Wireless Propag. Lett., vol. 14, pp. 1754-1757, 2015.

[16] S. Gupta, Z. Briqech, A. R. Sebak, and T. A. Denidni, "Mutual-Coupling Reduction Using Metasurface Corrugations for $28 \mathrm{GHz}$ MIMO Applications,” IEEE Antennas Wireless Propag.Lett., vol. 16, pp. 1401-1404, 2017.

[17] Kin-Lu Wong, Bo-Wei Lin, Wei-Yu Li. Dual-band dual inverted-F/loop antennas as a compact decoupled building block for forming eight 3.5/5.8-GHz MIMO antennas in the future smartphone. Microw Opt Technol Lett. 2017;572715-2721.

[18] B. P. Chacko, G. Augustin, and T. A. Denidni, "Tilted beam MPA with broad-useful bandwidth,” IET Microwave., Antennas Propag., vol. 11, no. 4, pp. 471-476, 2017.

[19] NiamatHussain, Min-JooJeong, Jiwoong Park, And Nam Kim, “A Broadband Circularly Polarized Fabry-Perot Resonant Antenna Using A Single-Layered PRS for 5G MIMO Applications", IEEE Access, Vol. No.7,pp. 42897-42907, 
[20] P. Gao, S. He, X. Wei, Z. Xu, N. Wang, and Y. Zheng, "Compact printed UWB diversity slot Antenna with 5.5-GHz band-notched characteristics," IEEE Antennas Wireless Propag. Lett., vol. 13, pp. 376-379, 2014.

[21] Richa Chandel, Anil Kumar Gautam, Karumudi Rambabu. "Tapered Fed Compact UWB MIMO Diversity Antenna with Dual Band-Notched Characteristics", IEEE Transactions on Antennas and Propagation, 2018. 